\title{
Pharmacological treatments for tobacco dependence
}

\author{
K.O. Fagerström* and C.A. Jiménez-Ruiz\#
}

ABSTRACT: There are currently three licensed therapies for smoking cessation: nicotine replacement (NR), bupropion and varenicline.

NR can be indicated for: 1) aid in abrupt cessation; 2) gradual reduction in order to quit smoking; 3) temporary abstinence; and 4) smoking reduction maintenance. A meta-analysis has found that the relative risk of abstinence for any form of NR relative to control was 1.6. It has been found that starting NR treatment 1-3 weeks before smoking cessation and combining NR products, usually patch and gum, increases efficacy. Recently some new nicotine administration forms, i.e. lozenge, mouth spray and a pouch, have been developed. They seem to have the potential to relieve cravings faster than the current high-dose gum, and also be more preferred.

Varenicline is a selective partial agonist at the $\alpha_{4} \beta_{2}$ nicotinic acetylcholine receptors (nAChR). It decreases cravings and alleviates the symptoms of withdrawal. It can also reduce the rewarding and reinforcing effects of nicotine. Trials have shown varenicline to have increased efficacy relative to bupropion. Varenicline has also been compared with NR (21 $\mathrm{mg}$ transdermal patch) in one randomised study. Abstinence at the end of treatment at 12 weeks was significantly increased for varenicline $(56 \%)$ compared with for nicotine patch $(43 \%)$. Some post-marketing reports have expressed concern about psychiatric adverse effects, such as aggression, depression and suicides. The European Medicines Agency and the Food and Drug Administration of the USA are monitoring reported side-effects, but so far no confirmed casual relationship between these adverse effects and varenicline has been established.

Bupropion inhibits neuronal re-uptake of dopamine and norepinephrine and is an antagonist on the nAChR. Its efficacy, compared with placebo, has been proved in several meta-analyses. A recent study suggests that longer pre-cessation use of bupropion, e.g. for 4 weeks, can improve efficacy results.

Under development for the treatment of tobacco dependence are cannabinoid antagonists, immunotherapy against nicotine, monoaminooxidase inhibitors, dopamine receptor D3 receptor antagonists and partial agonists, glutamatergic and GABA-ergic compounds and novel selective nicotine cholinergic receptor agonists and antagonists.

KEYWORDS: Bupropion, nicotine replacement, smoking cessation, varenicline

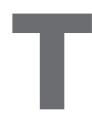
obacco smoking is gaining in recognition as a risk factor not only for respiratory disorders but also diseases in the cardiovascular system and cancer. Maybe less well known are the harmful effects of smoking during pregnancy. Therefore, the impetus to treat tobacco smoking is becoming stronger and upto-date information is needed. There is also a growing acceptance of tobacco dependence as a dependence disorder equally as strong as dependencies to other drugs, such as alcohol and opioids [1]. Therefore, treating tobacco dependence with only psychological support is suboptimal, although supportive therapy by itself is effective. The main conclusions from the recently updated USA guidelines for the treatment of tobacco dependence are: 1) there is stronger evidence than previously thought that counselling is a critical part of tobacco cessation; 2) the most effective pharmacological treatments are varenicline and nicotine patch in combination with an oral product; 3) brief interventions should be provided to all smokers, regardless of intention to quit, because of the cost-effectiveness; 4) more treatment is given if physicians are trained and treatment is reimbursed; and 5) evidence is not available to endorse the use of medications by adolescents, pregnant smokers, light smokers $\left(<10\right.$ cigarettes $\cdot$ day $\left.^{-1}\right)$ or smokeless tobacco users [2].
AFFILIATIONS

*Smoker's Information Centre and

Fagerstrom Consulting, Helsingborg, Sweden.

${ }^{\text {\#} S m o k e r ' s ~ C l i n i c, ~ G e n e r a l ~ D i r e c t i o n ~}$ of Primary Care, Community of Madrid, Madrid, Spain.

\section{CORRESPONDENCE}

K.O. Fagerström

Smoker's Information Centre and

Fagerstrom Consulting

Berga Alle 1

25452 Helsingborg

Sweden

Fax: 4642165760

E-mail: karl.fagerstrom@swipnet.se

STATEMENT OF INTEREST

K.O. Fagerström has consulted for most companies with an interest in the treatment of tobacco dependence and for all companies whose products are mentioned here, as well as holding stock in one of them, NicoNovum. K.0. Fagerström has also received reimbursement for attending symposia and fees for speaking. C.A. Jiménez-Ruiz undertakes research and consultancy for manufacturers of smoking cessation medications, and has also received reimbursement for attending symposia and fees for speaking and organising education.

European Respiratory Review Print ISSN 0905-9180 Online ISSN 1600-0617 
There are currently three licensed therapies: nicotine replacement (NR), bupropion and varenicline. Nortriptyline and clonidine also have documented efficacy but are not licensed on the indication. The bulk of the present overview will be concerned with a discussion of new aspects and developments of NR and the most recent therapy: the selective nicotinic receptor partial agonist varenicline. Bupropion will be covered more briefly.

\section{NICOTINE REPLACEMENT}

The most recent Cochrane meta-analysis has identified 111 trials with over 40,000 participants validated to a primary comparison between any type of NR and a placebo or non-NR control group. The relative risk (RR) of abstinence for any form of NR relative to control was 1.58 (95\% confidence interval (CI) $1.50-1.66)$. The RR for each formulation was 1.43 (95\% CI 1.33 1.53; 53 trials) for nicotine gum; 1.66 (95\% CI 1.53-1.81; 41 trials) for nicotine patch; 1.90 (95\% CI 1.36-2.67; four trials) for nicotine inhaler; 2.00 (95\% CI 1.63-2.45; six trials) for oral tablets/lozenges; and 2.02 (95\% CI 1.49-3.73; four trials) for nicotine nasal spray [3].

\section{Indications for NR}

The most commonly used indication for NR is aid in abrupt cessation, but additional uses are also licensed in some countries, such as for: gradual reduction to quit; temporary abstinence, i.e. for short periods of abstinence where smoking is not allowed; and maintenance of reduction.

It has been realised that unaided quitters often reduce their smoking as a prelude to cessation [4]. NR has been investigated as an aid in reduction of smoking among smokers not willing to quit. Two meta-analyses have found that for smokers who do not want to quit but want to reduce their smoking, the use of NR compared with placebo increased the likelihood that they would make a cessation attempt, and that they succeeded more often with the cessation $[2,5]$. Five studies were used in the meta-analyses and the main finding was that the use of NR more than doubled the likelihood that a smoker would be abstinent at 12 months (odds ratio (OR) 2.5, $95 \%$ CI 1.7-3.7) [2]. In a pooled analysis of eight trials, STEAD and LANCASTER [5] found that NR significantly increased the odds of reducing the number of cigarettes smoked daily by $\geqslant 50 \%$ compared with placebo (OR 2.02, 95\% CI 1.55-2.62). Moreover, the use of NR also significantly increased the odds of cessation (OR 1.9, 95\% CI 1.46-2.47). Reduction of tobacco consumption has been defined as the decrease in the number of cigarettes smoked daily by $\geqslant 50 \%$. The reduction should be verified by biochemical measures, e.g. expired air carbon monoxide levels.

A smoker in temporary abstinence can be defined as a smoker who does not want to quit and, for different reasons, must refrain from smoking during a period of time, e.g. when the smoker is at home, at the workplace or on public transport. In these situations some smokers, usually those who are more dependent on nicotine, can suffer from cravings and nicotine withdrawal syndrome and the use of NR has been recommended in order to alleviate these symptoms. Moreover, there are two different occasions where temporary abstinence could be associated with health benefits and even with a significant increase in the smoking cessation rate. Clinical studies have demonstrated that smoking cessation 4-8 weeks before surgery is associated with a significant decrease in the rate of surgical complications [6, 7]. Conversely, there is strong evidence that hospitalisation is associated with an increased rate of spontaneous smoking cessation compared with the general population. It has been found that 1-yr self-reported tobacco abstinence rates after general hospitalisation tend to be higher than the rate of spontaneous cessation in the general population $(\sim 10-15 \%$ versus $3-5 \%$, respectively) [7]. Taking these considerations into account, it can be concluded that health professionals should recommend temporary abstinence to those smokers unwilling to quit, and those who are in elective surgery or hospitalised. The use of NR is effective and safe in order to help them maintain temporary abstinence [6-14].

\section{New developments to increase the efficacy of NR}

\section{Combination of NR products}

Underdosing, i.e. replacing only a part of the nicotine taken in from smoking, is very common. A method to ameliorate the underdosing has been to combine several NR products, most commonly as patch plus gum [15, 16]. There is evidence from a meta-analysis that combining a nicotine patch with an oral form of NR was more effective than a single type of NR [3]. Moreover, it should be noted that according to recently updated USA Smoking Cessation Guidelines, the medication treatment that produced the largest effects on abstinence rates was long-term nicotine patch therapy ( $>14$ weeks) plus ad libitum oral NR [2].

Increasing nicotine uptake simply by using higher doses of transdermally absorbed nicotine has yielded some, but generally marginally, higher success rates $[17,18]$. The advantage of increasing the dose by combining a patch with a more acutely working administration form is that it allows the patient to do something to combat an acutely occurring craving.

Administration forms with more rapid release and craving relief It is not only the dose per se that determines the effect on craving and other withdrawal symptoms, but also the speed of delivery. The nicotine nasal spray, which has the fastest uptake of nicotine among the traditional NR products, has been found to reduce craving faster than the $4 \mathrm{mg}$ gum, although less nicotine is delivered by the nasal spray [19].

Very little product development, in terms of more aggressive and effective nicotine delivery, has occurred in the NR field despite the fact that scientists and clinicians have pleaded for improvements, usually in terms of faster nicotine uptake and in higher doses, in order to better mimic the pharmacokinetics of the cigarette. Recently, some new formulations from NicoNovum (Helsingborg, Sweden) have been tested: a mouth spray and a small teabag-like pouch to be fitted in under the upper lip against the gum. Additionally, chewing gums and lozenges that release nicotine faster have been tested. In studies on smokers stopping for 1 day, lozenge, mouth spray and pouch were compared with the Nicorette gum $4 \mathrm{mg}$ on craving and other withdrawal symptoms and preference variables. Participants tried all products (mouth spray, lozenge and pouch) with a wash-out period in between. It was found that $2 \mathrm{mg}$ nicotine from mouth spray (1 $\mathrm{mg}$ per actuation) and $4 \mathrm{mg}$ nicotine from the pouch reduced craving more and faster 
than the $4 \mathrm{mg}$ gum and were significantly more liked than the $4 \mathrm{mg}$ Nicorette gum [20]. In figure 1, the reduction in cravings after the first administration of pouch $(n=30)$ and mouth spray and lozenge $(n=47)$ compared with $4 \mathrm{mg}$ Nicorette gum and placebo is shown.

Mouth spray was more preferred than $4 \mathrm{mg}$ Nicorette gum for satisfaction, helpfulness, pleasantness and ease of use, and more subjects would recommend a mouth spray to others. The $4 \mathrm{mg}$ gum was less embarrassing to use than the spray. The pouch was better than gum on all preference variables. The preference ratings for these products can be seen in figures 2 and 3. Total compliance with abstinence during the test day in the pouch study was $75 \%, 52 \%$ and $41 \%$ for pouch, active gum and placebo pouch, respectively [20].

The chewing gums of $1.5 \mathrm{mg}$ and $3 \mathrm{mg}$ nicotine strength, which deliver all the nicotine in $10 \mathrm{~min}$ were not included in these studies, but the benefit from the gum may be that it requires only $10 \mathrm{~min}$ chewing compared with the $25-30 \mathrm{~min}$ chewing the presently available gums. The 1.5 and $3 \mathrm{mg}$ gums have the same nicotine delivery characteristics as the currently available 2 and $4 \mathrm{mg}$ nicotine doses (NicoNovum; data on file). In another study in smokers ready to quit, the mouth spray, oral inhaler and $2 \mathrm{mg}$ nicotine gum were all to be tested by the
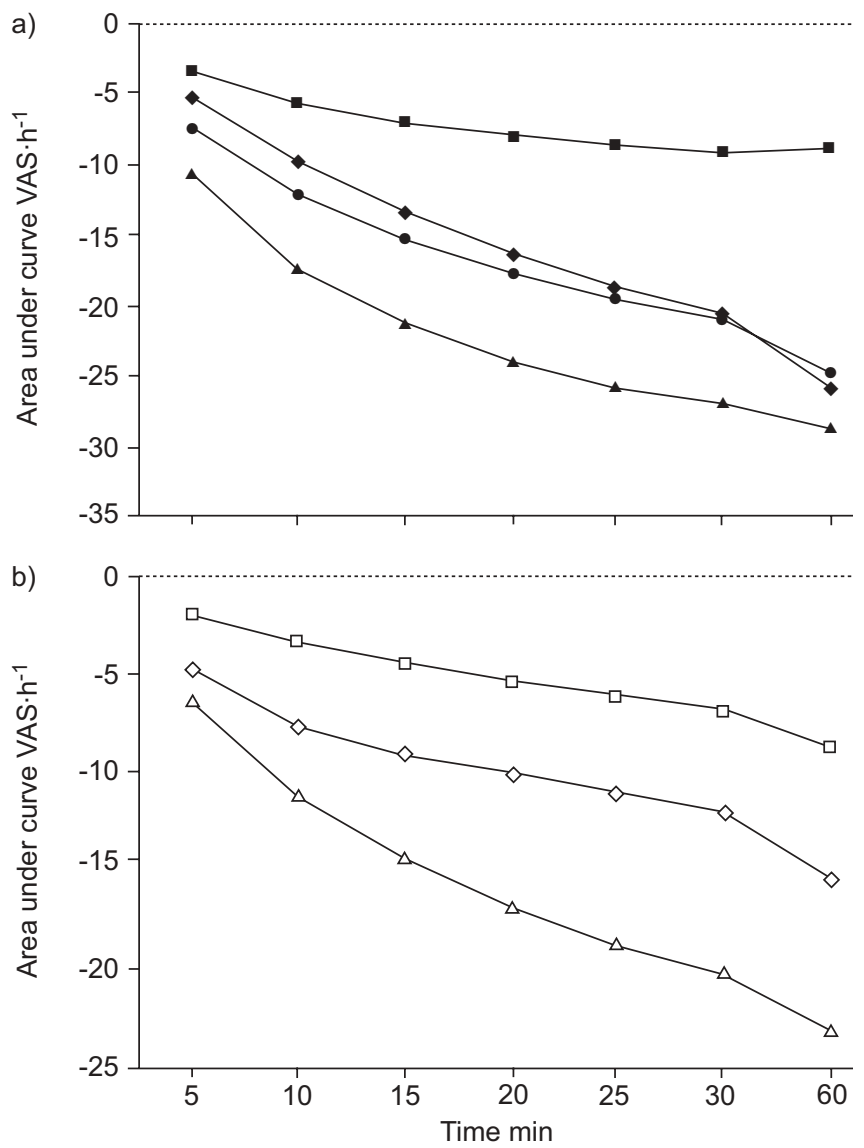

FIGURE 1. Reduction in craving expressed as area under the curve during 60 min for a) Nicorette $4 \mathrm{mg}$ gum $(\diamond)$, mouth spray $(\mathbf{\Delta})$, lozenge $(\bullet)$ and placebo lozenge $(\boldsymbol{\square})$; and b) Nicorette $4 \mathrm{mg}$ gum $(\diamond)$, pouch $(\triangle)$ and placebo pouch $(\square)$ [20]. VAS: visual analogue scale. smokers the week before cessation. A total of $54 \%$ preferred the mouth spray, compared with $28 \%$ for gum and $18 \%$ for the oral inhaler [21]. These new products from NicoNovum are so far only available in Sweden.

\section{Starting with NR before or on the day of cessation}

Up to relatively recently, the labelling of NR products has mandated that they could only be used after cessation. Four randomised controlled clinical trials have tested pre-cessation familiarisation with NR. All of the studies showed improved long-term cessation rates for pre-cessation use [22-25].

A recent meta-analysis has evaluated the incremental efficacy of starting nicotine patch treatment prior to cessation, compared with the current regimen of starting patch treatment on the target cessation day. It was found that pre-cessation patch treatment produced a significant increase in cessation rates at 6 months (OR 2.17, 95\% CI 1.46-3.22) compared to current regimens starting patch treatment on the day of cessation [26].

The mechanism of action for this is not well known. It can be imagined that familiarisation with gum, nasal spray and other buccally absorbed products would be beneficial but most of the trials have used nicotine patches [26]. Therefore, experiencing an effect manifesting itself in reduced smoking and dependence and improved self-efficacy may contribute to the increased efficacy. The most common length of the precessation use has varied between 1 and 3 weeks.

\section{Discontinuing or continue use when lapsing}

The dominating practice has been to inform patients that smoking just one cigarette is very likely to damage the attempt and lead to full relapse. Therefore, therapy is often interrupted and stopped when a lapse occurs. Although it may be important and productive to strongly warn against just one cigarette, there is a rising concern among clinicians and researchers over whether treatment should be stopped. It has also been suggested that the effect of the treatment is not enough and that the dose and frequency of use should be adjusted upwards. However, at the present time no trial has proved this assumption.

\section{VARENICLINE}

\section{Pharmacology}

Varenicline's synthesis came from basic research revealing the structure and functional properties of nicotinic acetylcholine receptors (nAChRs) and the effects of cytisine, a useful ligand for studying $\mathrm{nAChRs}$ [27]. Interestingly, cytisine has been historically used to help people stop smoking in Eastern Europe [28, 29].

Based on these observations, the $\alpha_{4} \beta_{2}$ receptor was identified as a potential target for a smoking cessation drug [30]. Varenicline was developed to have a high affinity for $\alpha_{4} \beta_{2}$ $\mathrm{nAChR}$ in the mesolimbic dopamine system [29] and to act as a selective partial agonist of the $\alpha_{4} \beta_{2}$ nAChR. Like other partial agonists (e.g. buprenorphine), varenicline has both agonist and antagonist effects. Binding at $\alpha_{4} \beta_{2} \mathrm{nAChR}$ is hypothesised to decrease the craving for nicotine and alleviate the symptoms of withdrawal (agonist effects). In addition, blocking of nicotine's binding at these receptors is hypothesised to reduce nicotineinduced dopamine release and, consequently, its rewarding/ reinforcing effects (antagonist effects) [29]. 


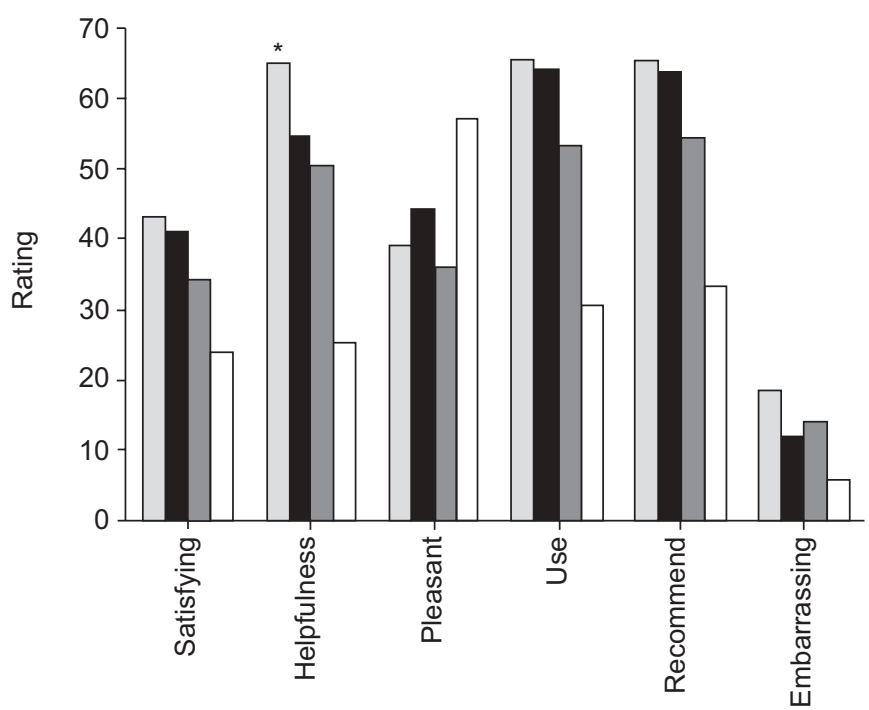

FIGURE 2. Mean subjective ratings of product preference $(n=47)$. NicoNovum mouth spray; $\mathbf{\square}$ : NicoNovum lozenge; $\mathbf{\square}$ : Nicorette gum; $\square$ : placebo lozenge. *: $p<0.05$.

Varenicline has an elimination half-life of $\sim 24 \mathrm{~h}$ [31]. The maximum absorption of varenicline occurs within $\sim 3-4 \mathrm{~h}$ following oral administration, and steady state conditions are typically reached within 4 days following regular doses in healthy adults [32]. Less than $10 \%$ of varenicline is excreted as metabolites and $\sim 92 \%$ of varenicline is excreted unchanged in urine, indicating that the major route of clearance for varenicline is renal excretion [33].

\section{Varenicline in clinical use}

Phase-II trials have suggested that varenicline has increased efficacy relative to bupropion and placebo, that titrating dose was beneficial for minimising side-effects and that $1 \mathrm{mg}$ b.i.d. was the optimal dose. In the two phase- 3 trials, participants were randomised to receive varenicline $1 \mathrm{mg}$ uptitrated, bupropion SR $150 \mathrm{mg}$ b.i.d. or placebo [32, 34]. The recommended use of varenicline thereafter has been $0.5 \mathrm{mg}$ daily for 3 days, $0.5 \mathrm{mg}$ b.i.d. for 4 days, then $1 \mathrm{mg}$ b.i.d. for 11 weeks, and cessation to occur during week two.

Week 9-12 and week 9-52 continuous abstinence rates were significantly greater for varenicline than placebo in both trials (fig. 4) [32, 34]. Varenicline also achieved significantly greater efficacy over bupropion SR in weeks 9-12 in both studies and this was maintained for weeks 9-52 in one trial [34]. In the other trial, although the effect size was similar, this did not quite reach statistical significance [32].

Safety analyses of pooled data based on the two phase 3 trials cited above [32, 34] were conducted based on 2,045 subjects who received at least one dose of study medication (varenicline, $n=692$; bupropion SR, $n=669$; or placebo, $n=684$ ) [35]. Varenicline demonstrated an acceptable safety profile. The most commonly reported adverse effects in the pooled varenicline group were nausea $(29 \%)$, insomnia $(14 \%)$ and headache $(14 \%)$. A $29 \%$ nausea figure seems high and was greater than nausea events reported in the bupropion SR participants (10\%) and placebo participants (9\%) [35].

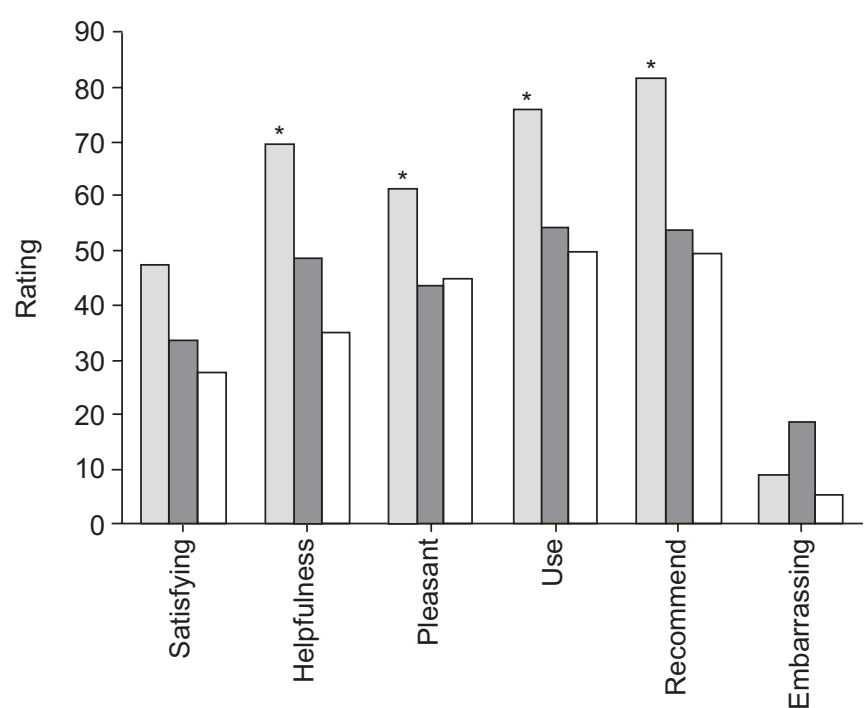

FIGURE 3. Mean subjective ratings of product preference $(n=30)$. NicoNovum pouch; $\square$ : Nicorette gum; $\square$ : placebo pouch. *: $p<0.05$

However, discontinuation from study treatment due to nausea was rare and occurred in $3 \%$ of the varenicline participants, compared with $1 \%$ of the bupropion SR participants and $<1 \%$ of the placebo group. The onset and incidence of nausea peaked in the second week of treatment and reduced thereafter [35]. Discontinuation from treatment for any reason occurred most frequently in the bupropion group (14\%), followed by varenicline (10\%) and then placebo (8.2\%) [35].

The efficacy of varenicline over placebo has also been demonstrated in Asian participants from Japan [36], Taiwan and South Korea [37]. Safety profiles in these Asian studies were similar to those seen in Western studies.

\section{Varenicline in comparison with NR}

Varenicline has been compared with NR in two studies. A nonrandomised study compared varenicline with various NR products in a smokers' clinic giving seven group therapy sessions, in addition to the medicine in smokers with and without prior or current mental illnesses [38]. Results for NR were based on patients treated before varenicline was available and thereafter patients were prescribed varenicline. Therefore, there was a novelty factor in the study that could not be controlled for. The cessation rate at 6 weeks (the only time point reported) was higher for varenicline than use of one NR product (72 versus 61\%; OR 1.7); however, varenicline did not result in greater cessation than use of two NR products. There were significantly more side-effects with varenicline. The most common were nausea, disturbed sleep, vivid dreams, drowsiness and constipation. Varenicline was similarly effective in those with and without mental illness and showed no evidence of worsening the mental illnesses [38].

The second study was a randomised comparison of varenicline with NR (21 mg transdermal patch) [39]. Abstinence at the end of treatment at 12 weeks was $56 \%$ for varenicline and $43 \%$ for nicotine patch $(\mathrm{p}<0.001)$. The effect size was similar at 52 weeks, 26 versus 20\%, but was no longer statistically significant. Varenicline also showed benefits over transdermal 


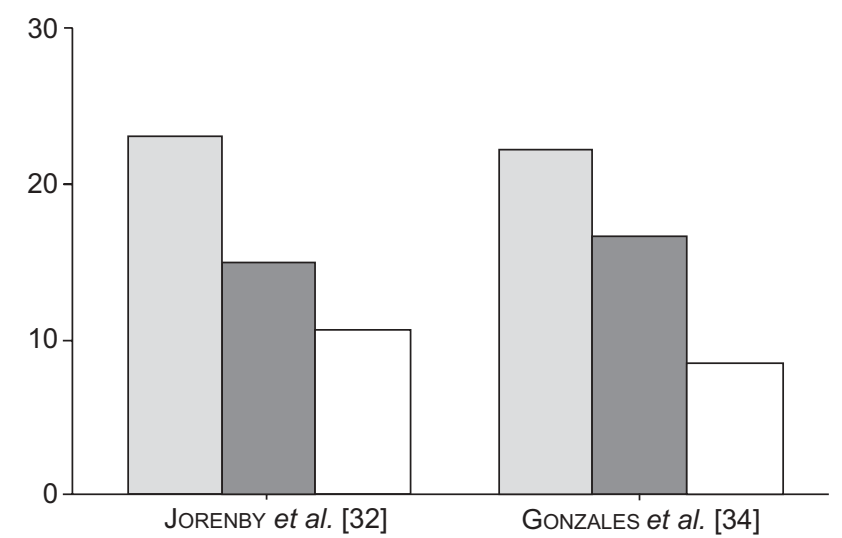

FIGURE 4. Continuous smoking cessation rate (\%) between week 9 and 52 in two studies $[32,34]$. - : varenicline $(n=343$ and $n=349$ for the studies by JORENBY et al. [32] and GonZALES et al. [34], respectively); $\mathbf{a}$ : buproprion ( $\mathrm{n}=340$ and $n=329$, respectively); $\square$ : placebo $(n=340$ and $n=344$, respectively).

nicotine on craving, withdrawal symptoms and reduction of smoking satisfaction [39]. How much the novelty of varenicline has influenced the results with regard to the established NR therapy is not known. Varenicline demonstrated an acceptable safety profile, although there were more reported adverse events in the varenicline group than the NR group. The most frequent adverse effect in the varenicline group was nausea (varenicline 37\%, NR 10\%), followed by insomnia (varenicline $21 \%$, NR 19\%), and headache (varenicline 19\%, NR 10\%) [39]. There was also one report of suicidal ideation in the varenicline group [39]. Many adverse events from varenicline have been reported, particularly in studies from the USA. A recent report that was not peer reviewed was released on the internet from the Institute for Safe Medication Practices [40]. This report found that varenicline use had been associated with cases of agitation, aggression, depressed mood, suicidal ideation and completed suicides. Accidents were also reported among the roughly 4 million patients that had been using varenicline in the USA. The report fails to set the numbers of adverse events in the context of the numbers and characteristics of people using the medication, and it does not address the potential for media reports of particular kinds of adverse events to generate further spurious reports. With regard to the first problem, it is obviously not possible to determine whether the numbers of events are greater than would be expected without knowing the rate of events in heavy smokers who are in the process of stopping smoking. With regard to the second problem, one has to recognise that events such as suicidal ideation, and even suicide attempts, can be prompted by press reports of such events in others.

Since very little of this has been seen in the clinical trials, where basically healthy smokers were recruited, it is possible that the reported type of adverse effects occur more frequently in smokers with comorbidities. There is also a possibility that due to the strong anti-smoking climate in the USA over the past $\sim 20$ yrs the remaining smokers are more dependent [41] and use smoking to cope with clinical and subclinical psychiatric comorbidities [42]. The Food and Drug Adminstration of the USA has recently advised providers and users of varenicline to monitor changes in behaviour but it has also stated that there is no confirmed casual relationship between these symptoms and varenicline [43].

Further trials assessing varenicline as a smoking cessation aid are underway in participants with cardiovascular disease (www.clinicaltrials.gov identifier NCT00282984) and chronic obstructive pulmonary disease (www.clinicaltrials.gov identifier NCT00285012). More than 20 other trials with varenicline are listed on topics such as: mood in depressed outpatient smokers; varenicline as an adjunct to smoking cessation in schizophrenics; mecamylamine and varenicline in schizophrenia; efficacy and safety of varenicline tartrate in comparison with placebo in smoking cessation when subjects are allowed to set their own cessation date; varenicline to prompt cessation in ambivalent smokers; and the efficacy of bupropion and varenicline in combination.

\section{BUPROPION}

The mechanism of action of this drug is not completely known. However, bupropion acts on the nucleus accumbens, inhibiting neuronal reuptake of dopamine. This effect would explain the reduction in craving experienced by smokers using bupropion. Some evidence suggests this effect to be significantly greater in smokers with a special genotype: DRD2-taql1 A2/A2 [44]. Bupropion also inhibits neuronal reuptake of noradrenaline in the nucleus ceruleus [44], and is a noncompetitive functional inhibitor of nAChRs. This antinicotinic activity may contribute to its efficacy in the treatment of nicotine dependence [45].

A meta-analysis that evaluated the efficacy of bupropion in 31 clinical trials found an OR of 1.94 (95\% CI 1.72-2.19) [46]. The efficacy of bupropion is related to the dose used, with mean plasma drug concentration and with the blood concentration of the drug metabolites [47]. Smokers who used bupropion at a dose of $100 \mathrm{mg}, 150 \mathrm{mg}$ or $300 \mathrm{mg}$ daily were 1.42, 1.69 and 2.84 times more likely to quit smoking, respectively, than those who used placebo [48]. Bupropion is manufactured as a sustained release tablet that contains $150 \mathrm{mg}$ active ingredient.

A recent study has found that those smokers who metabolised nicotine faster had better outcome. It was found that at the end of the 10-week treatment phase, slow metabolisers had equivalent qcessation rates with placebo or bupropion (32\%) and fast metabolisers had low cessation rates with placebo (10\%) but significantly higher rates with bupropion (34\%). At the 6-month follow-up, the relationship between the speed of metabolism and cessation remained similar, but differences were no longer statistically significant [49].

Treatment with bupropion should be initiated about 1 week before the patient's cessation date, at an initial dose of

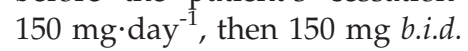

Preliminary evidence suggests that if bupropion is used for a longer period (4 weeks) before cessation, some extinction takes place and better success rates can be expected (L.W. Hawk, M.C. Mahoney, R.L. Ashare, et al., University at Buffalo, Buffalo, NY, USA; personal communication).

The usual length of treatment is 6-12 weeks, but bupropion can be used safely for much longer [47]. The most common adverse effects are insomnia and dry mouth. A small risk $(0.1 \%)$ of seizure is also associated with bupropion. Treatmentemergent hypertension can occur during treatment with 
bupropion, especially when it is used in combination with NR [44]. Bupropion is contraindicated in patients who have a history of seizures, serious head trauma, an eating disorder or concomitant use of medications that lower the seizure threshold [44].

Although bupropion is an antidepressant, and depression is linked to smoking and a marker for relapse, bupropion does not seem to have any better effect in depressed smokers or smokers with a history in depression. The mechanism of action in smoking cessation might be different from the one in depression [50].

\section{NEW MEDICATIONS}

There is an increasing interest in the development of additional compounds. Work is ongoing, with cannabinoid antagonists, immunotherapy against nicotine, monoaminooxidase inhibitors, dopamine receptor D3 receptor antagonists and partial agonists, glutamatergic and GABA-ergic compounds and novel selective nicotine cholinergic receptor agonists and antagonists also in the early stages of development.

\section{REFERENCES}

1 Nutt D, King LA, Saulsbury W, Blakemore C. Development of a rational scale to assess the harm of drugs of potential misuse. Lancet 2007; 369: 1047-1053.

2 Fiore MC, Jaen CR, Baker TB, et al. Treating tobacco use and dependence: 2008 update. Rockville, US Dept of Health and Human Services, 2008. Available from www.ahrq.gov/ path/tobacco.htm\#Clinic Last updated: May 2008.

3 Stead LF, Perera R, Bullen C, Mant D, Lancaster T. Nicotine replacement therapy for smoking cessation. Cochrane Database Syst Rev 2008; 1: CD000146.

4 Hughes J, Callas PW, Peters EN. Interest in gradual cessation. Nicotine Tob Res 2007; 6: 671-675.

5 Stead LF, Lancaster T. Interventions to reduce harm for continued tobacco use. Cochrane Database Syst Rev 2007; 3: CD005231.

6 Teadom A, Cropley M. Effects of preoperative smoking cessation on the incidence and risk of intraoperative and postoperative complications in adults smokers: a systematic review. Tob Control 2006; 15: 352-358.

7 Warner D. Pre-operative smoking cessation. The role of primary care providers. Mayo Clin Proc 2005; 80: 252-258.

8 France EK, Glasgow RE, Marcus AC. Smoking cessation interventions among hospitalized patients. What have we learned? Prev Med 2001; 32: 376-388.

9 Rigotti N, Munafo M, Stead LF. Interventions for smoking cessation in hospitalized patients. Cochrane Database Syst Rev 2007; 3: CD001837.

10 Cropley V, Theadom A, Pravettoni G, Webb G. The effectiveness of smoking cessation interventions prior to surgery. A sytematic review. Nicotine Tob Res 2008; 10: 407-412.

11 Warner MA, Offorf KP, Warner ME, Lennon RL, Conover MA, Jansson-Schumacher U. Role of preoperative cessation of smoking and other factors in post-operative pulmonary complications: a blinded prospective study of coronary artery bypass patients. Mayo Clin Proc 1989; 64: 609-616.
12 Warner MA, Divertie MB, Tinker JH. Preoperative cessation of smoking and pulmonary complications in coronary artery bypass patients. Anesthesiology 1984; 60: 380-383.

13 Sorensen LT, Karlsmark T, Gottrup F. Abstinence from smoking reduces incisional wound infection: a randomized controlled trial. Am Surg 2003; 238: 1-5.

14 Nakawaga M, Tanaka H, Tsukuma H, Kishi Y. Relationship between the duration of the pre-operative smoke-free period and the incidence of post-operative pulmonary complications after pulmonary surgery. Chest 2001; 120: 705-710.

15 Sweeney C, Fant R, Fagerström KO, McGovern JF, Henningfield JE. Combination nicotine replacement therapy for smoking cessation. CNS Drugs 2001; 15: 453-467.

16 Fagerström KO, Schneider NG, Lunell E. Effectiveness of nicotine patch and nicotine gum as individual vs combined treatment for tobacco withdrawal symptoms. Psychopharmacology 1993; 111: 271-277.

17 Tonnesen P, Paoletti P, Gustavsson G, et al. Higher dosage nicotine patches increase one-year smoking cessation rates: results from the European CEASE trial. Collaborative European Anti-Smoking Evaluation. Eur Respir J 1999; 13: 238-246.

18 Hughes JR, Lesmes GR, Hatsukami DK, et al. Are higher doses of nicotine replacement more effective for smoking cessation. Nicotine Tob Res 1999; 1: 169-174.

19 Hurt R, Offord KP, Croghan IT, et al. Temporal effects of nicotine nasal spray and gum on nicotine withdrawal symptoms. Psychopharmacology 1998; 140: 98-104.

20 McRobbie H, Thornley S, Ruey-bin L, et al. The effects of three novel nicotine replacement therapies on the relief of tobacco withdrawal sypmtoms. Presentation at the annual meeting of the Society for Research on Nicotine and Tobacco. Eugene, Portland, 2008. Available from www.healthnz.co.nz/NicoNovumSRNT2008Poster.pdf

21 Bolliger C, van Biljon, Axelsson A. A nicotine mouth spray for smoking cessation: a pilot study of preference, safety and efficacy. Respiration 2006; 74: 196-201.

22 Herrera N, Franco R, Herrera L, Partidas A, Rolando R, Fagerström KO. Nicotine gum, 2 and $4 \mathrm{mg}$, for nicotine dependence. A double-blind placebo-controlled trial within a behaviour modification support program. Chest 1995; 106: 447-451.

23 Schuurmans MM, Diacon AH, van Biljon X, Bolliger CT. Effect of pre-treatment with nicotine patch on withdrawal symptoms and abstinence rates in smokers subsequently quitting with the nicotine patch: a randomized controlled trial. Addiction 2004; 99: 634-640.

24 Rose JE, Behm FM, Westman EC, Kukovich P. Precessation treatment with nicotine skin patch facilitates smoking cessation. Nicotine Tob Res 2006; 8: 89-101.

25 Rose JE, Behm FM, Westman EC. Nicotine-mecamylamine treatment for smoking cessation: the role of pre-cessation therapy. Exp Clin Psychopharmacol 1998; 6: 331-343.

26 Shiffman S, Fergusson SG. Nicotine patch therapy prior to quitting smoking: a meta-analysis. Addiction 2008; 103: 557-563.

27 Pabreza LA, Dhawan S, Kellar KJ. $\left[{ }^{3} \mathrm{H}\right]$ cytisine binding to nicotinic cholinergic receptors in the brain. Mol Pharmacol 1991; 39: 9-12. 
28 Etter J-F. Cytisine for smoking cessation: a literature review and meta-analysis. Arch Intern Med 2006; 166: 1553-1559.

29 Coe JW, Brooks PR, Vetelino MG, et al. Varenicline: an $\alpha_{4} \beta_{2}$ nicotinic receptor partial agonist for smoking cessation. J Med Chem 2005; 48: 3474-3477.

30 Rollema H, Coe JW, Chambers LK, Hurst RS, Stahl SM, Williams KE. Rationale, pharmacology and clinical efficacy of partial agonists of $\alpha_{4} \beta_{2}$ nicotinic acetylcholine receptors for smoking cessation. Trends Pharmacol Sci 2007; 28: 316-325.

31 Faessel HM, Smith BJ, Gibbs MA, Gobey JS, Clark DJ, Burstein AH. Single-dose pharmacokinetics of varenicline, a selective nicotinic receptor partial agonist, in healthy smokers and non-smokers. J Clin Pharmacol 2006; 46: 991-998.

32 Jorenby DE, Hays JT, Rigotti NA, et al. Efficacy of varenicline, an $\alpha_{4} \beta_{2}$ nicotinic acetylcholine receptor partial agonist, vs placebo or sustained-release bupropion for smoking cessation: a randomized controlled trial. JAMA 2006; 296: 56-63.

33 Obach RS, Reed-Hagen AE, Krueger SS, et al. Metabolism and disposition of varenicline, a selective $\alpha_{4} \beta_{2}$ acetylcholine receptor partial agonist, in vivo and in vitro. Drug Metab Dispos 2006; 34: 121-130.

34 Gonzales D, Rennard SI, Nides M, et al. Varenicline, an $\alpha_{4} \beta_{2}$ nicotinic acetylcholine receptor partial agonist, vs sustained-release bupropion and placebo for smoking cessation: a randomized controlled trial. JAMA 2006; 296: 47-55.

35 Nides M, Glover E, Reus V, et al. Varenicline versus bupropion for smoking cessation: a pooled analysis. Am J Health Behav 2008; 32: 664-675.

36 Nakamura M, Oshima A, Fujimoto Y, Maruyama M, Ishibashi T, Reeves KR. Efficacy and safety of varenicline, an $\alpha_{4} \beta_{2}$ nicotinic acetylcholine receptor partial agonist, in a 12-week, randomized, placebo-controlled, dose-response study with 40 -week follow-up for smoking cessation in japanese smokers. Clin Ther 2007; 29: 1040-1056.

37 Tsai S-T, Cho H-J, Cheng H-S, et al. A randomized, placebo-controlled trial of varenicline, a selective $\alpha_{4} \beta_{2}$ nicotinic acetylcholine receptor partial agonist, as a new therapy for smoking cessation in asian smokers. Clin Ther 2007; 29: 1027-1039.

38 Stapleton JA, Watson L, Spirling LI, et al. Varenicline in the routine treatment of tobacco dependence: a pre-post comparison with nicotine replacement therapy and an evaluation in those with mental illness. Addiction 2008; 103: 146-154.

39 Aubin H-J, Bobak A, Britton JR, et al. Varenicline versus transdermal nicotine patch for smoking cessation: results from a randomised, open-label trial. Thorax 2008; 63: 717-724.

40 Moore TJ, Cohen MR, Furberg CD. The Institute for Safe Medication Practices. Strong Safety Signal Seen for New Varenicline Risks. www.ismp.org/docs/vareniclineStudy.asp Date last updated: May 21, 2008.

41 Fagerström K, Furberg H. A comparison of the Fagerström Test for Nicotine Dependence and smoking prevalence across countries. Addiction 2008; 103: 841-845.

42 Lasser K, Boyd JW, Woolhandler S, Himmelstein DU, McCormick D. Smoking and mental illness: a populationbased prevalence study. JAMA 2000; 284: 2606-2610.

43 U.S. Food and Drug Administration. Early communication about an ongoing safety review: varenicline (marketed as Chantix). www.fda.gov/cder/drug/early_comm/varenicline. htm Date last accessed: January 14, 2008. Date last updated: February 1, 2008.

44 Lerman C, Shields PG, Wileyto EP, et al. Effects of dopamine transporter and receptor polymorphins on smoking cessation in a bupropion clinical trial. Health Psychol 2003; 22: 541-548.

45 Cryan JF, Bruijnzeel AW, Skjei KL, Markou A. Bupropion enhances brain reward function and reverses the affective and somatic aspects of nicotine withdrawal in the rat. Psychopharmacology (Berl) 2003; 168: 347-358.

46 Hughes JR, Stead LF, Lancaster T. Antidepressants for smoking cessation. Cochrane Database Syst Rev 2007; 1: CD000031.

47 Hays JT, Hurt RD, Rigotti NA, et al. Bupropion SR for pharmacologic relapse prevention after smoking cessation. A randomised controlled trial. Ann Intern Med 2001; 135: 423-433.

48 Johnston JA, Fiedler-Kelly J, Glover ED, Sachs DP, Grasela TH, Deveaugh-Geiss J. Relationship between drug exposure and the efficacy and safety of bupropion SR for smoking cessation. Nicotine Tob Res 2001; 2: 131-140.

49 Patterson F, Schnoll R, Wileyto E, et al. Toward personalized therapy for smoking cessation: a randomised placebo controlled trial for bupropion. Clin Pharmacol Ther 2008; 84: 320-325.

50 Lerman C, Niaura R, Collins BN, et al. Effects of bupropion on depression symptoms in a smoking cessation clinical trial. Psychol Addict Behav 2004; 18: 362-366. 